\title{
Standardising assessment and documentation of pouchoscopy
}

\author{
Valerie Annerijn van der Ploeg, Yasuko Maeda, Omar D Faiz, \\ Ailsa L Hart, Susan K Clark
}

Department of Surgery, St Mark's Hospital, Harrow, UK

Correspondence to Susan K Clark, Department of Surgery, St. Mark's Hospital, London HA1 3UJ, UK; s.clark8@ nhs.net

Received 14 November 2017 Revised 6 February 2018 Accepted 24 February 2018 Published Online First 13 March 2018

\section{ABSTRACT \\ Background/aims Variation in quality of reporting on endoscopic procedures is a common clinical problem. Findings are not documented in a standardised manner and there is a tendency towards reporting abnormal findings only. This study aimed to review quality of flexible pouchoscopy reports and to develop a standardised reporting template.}

Methods Ileo-anal-pouch experts $(n=5)$ compiled a list of items that should be documented at flexible pouchoscopy. Reports were reviewed retrospectively for their completeness compared with the template. The template was then introduced and quality of reports was analysed prospectively.

Results One hundred and twenty-one reports produced between March 2015 and June 2015 were reviewed. Between August 2015 and November 2015, the template was introduced and reports were analysed. There was significant improvement in documentation of anus and perianal area (before template (B) 12\% to after template $(A) 51 \%, p<0.0001)$, rectal cuff ( $B$ : $55 \%$ to $A: 75 \%, p=0.01$ ), pouch-anal anastomosis ( $B$ : $37 \%$ to $A: 67 \%, p=0.0002$ ) and pouch inlet (B: $13 \%$ to $A: 41 \%, p<0.0001$ ). Pouch body was described in high percentage regardless of introduction of the template (B: 98\% to $A: 97 \%, p=0.61$ ).

Conclusions Documentation of pouchoscopy findings was suboptimal and introduction of a template improved documentation of flexible pouchoscopy significantly.

\section{INTRODUCTION}

Restorative proctocolectomy with the formation of ileal-pouch-anal anastomosis (RPC-IPAA) is a surgical option in patients with medically refractory ulcerative colitis (UC) and selected patients with familial adenomatous polyposis (FAP). This surgical procedure spares patients from having a permanent ileostomy; however, up to $30 \%$ of patients experience poor function or pouch-related symptoms at some stage. ${ }^{12}$ Due to an overlap in symptoms between the different causes of pouch dysfunction, pouch assessment and diagnosis can be challenging. A systematic approach is undoubtedly important. In 2008, McLaughlin et al designed an algorithm for investigation of patients in whom the cause of pouch dysfunction is not clear. ${ }^{2}$ Full investigation should consist of history taking, digital anal examination, laboratory evaluation and pouchoscopy and biopsy, with pouchogram and/or cross-sectional imaging of pelvis/abdomen in some cases. Flexible pouchoscopy is considered to be the most useful first-line investigation in diagnosing the cause of pouch dysfunction and is also used for routine follow-up in those with FAP or UC with previous cancer or dysplasia. The same group of authors designed a guideline concerning endoscopic investigation, providing endoscopists with procedure techniques, practical tips, sites to pay specific attention to and management of common findings at pouchoscopy. ${ }^{3}$ However, a description of what a full pouchoscopy report should contain is lacking.

Variation in quality of reporting on endoscopic procedures is a common clinical problem and has led to studies addressing the adequacy of reports. ${ }^{45}$ Findings are often not documented in a standardised manner and there is a tendency towards reporting abnormal findings only. Normal or negative findings are not always documented, but may be equally important in the diagnostic or therapeutic process. The majority of these studies were performed to improve reporting on colonoscopies in the context of colorectal cancer screening. However, this tendency of not reporting on normal findings is also seen in the reporting of pouchoscopy. Additionally, since the anatomy is entirely different 
after RPC-IPAA, the assessment of ileo-anal pouches should involve documentation of specific anatomical sites and specific elements that can be the cause of pouch dysfunction, which makes it difficult to use current colonoscopy reporting tools as a guide.

\section{Aims}

The primary aims of this study were to review the current quality of flexible pouchoscopy reports and to develop a standardised reporting template for pouchoscopy. Secondary aims were to implement this template to standardise pouchoscopy reports and identify whether the standard of documentation improved.

\section{METHODS}

The study was performed in a specialist endoscopy unit in a tertiary referral centre. The study consisted of two parts. First, a template for pouchoscopy reporting was developed. This template was then used to review the accuracy of reporting retrospectively. Subsequently, the template was implemented prospectively and used to monitor the standard of reporting and to verify the feasibility of the template itself.

\section{Design of the template}

As a framework, a list of sites of an ileo-anal pouch was drawn up, based on the anatomy. All anatomical sites at which pathology can occur were added. A group of ileo-anal pouch experts $(n=5)$, including gastroenterologists and colorectal surgeons with an interest in inflammatory bowel disease, were asked to suggest features they thought should be mentioned in a pouchoscopy report for each individual anatomical site. A format for the template was drawn up collating their suggestions, and the experts were asked to vote on items to be included or excluded in the template. Items with an overall total of three or more votes were included. A new format was designed and the experts were asked for their final opinion before the template was rolled out in the endoscopy unit.

To determine the endoscopic features of inflammation that are valuable in the assessment of pouchitis and should be included in the template, several such features were scored by gastroenterologists specialised in inflammatory bowel disease $(n=12)$. According to how much value each gastroenterologist assigned to each feature, the features were scored on a scale from 1 (not valuable) to 10 (very valuable). The responses from all 12 gastroenterologists were put together, and only features scoring 7 or higher were deemed valuable and included in the template.

\section{Review of pouchoscopy reports}

The designed template (table 1) was used to review the accuracy of reports of flexible pouchoscopy performed between 1 March 2015 and 2 June 2015

\begin{tabular}{|c|c|c|}
\hline \multirow[t]{2}{*}{ Anus/perianal } & \multicolumn{2}{|l|}{$\begin{array}{l}\text { Digital examination } \\
\text { (yes/no) }\end{array}$} \\
\hline & \multicolumn{2}{|l|}{$\begin{array}{l}\text { Abnormalities at anus } \\
\text { (yes/no) }\end{array}$} \\
\hline \multirow[t]{5}{*}{ Rectal cuff } & \multicolumn{2}{|l|}{ Length $(\mathrm{cm})$} \\
\hline & \multicolumn{2}{|l|}{$\begin{array}{l}\text { Inflamed surface } \\
\text { (yes/no) }\end{array}$} \\
\hline & \multicolumn{2}{|l|}{$\begin{array}{l}\text { Other abnormalities } \\
\text { (eg, polyps) }\end{array}$} \\
\hline & \multicolumn{2}{|l|}{ Biopsy (yes/no) } \\
\hline & \multicolumn{2}{|l|}{$\begin{array}{l}\text { Photo in retroflection } \\
\text { (yes/no) }\end{array}$} \\
\hline \multirow[t]{3}{*}{ Anastomosis } & \multicolumn{2}{|c|}{ Appreciable at digital examination (yes/no) } \\
\hline & \multicolumn{2}{|l|}{ Stenosis (yes/no) } \\
\hline & \multicolumn{2}{|l|}{ Defects (yes/no) } \\
\hline \multirow[t]{9}{*}{ Lower pouch } & \multirow[t]{3}{*}{ Inflammation features } & Severe erythema (yes/no) \\
\hline & & $\begin{array}{l}\text { Severe friability/contact bleeding } \\
\text { (yes/no) }\end{array}$ \\
\hline & & Erosion/ulceration (yes/no) \\
\hline & \multirow[t]{3}{*}{ Inflamed surface } & Affected (\%—where) \\
\hline & & Ulcerated (\%—where) \\
\hline & & $\begin{array}{l}\text { Inflamed suture lines only } \\
\text { (yes/no) }\end{array}$ \\
\hline & \multicolumn{2}{|l|}{$\begin{array}{l}\text { Other abnormalities } \\
\text { (eg, polyps) }\end{array}$} \\
\hline & \multicolumn{2}{|l|}{ Biopsy (yes/no) } \\
\hline & \multicolumn{2}{|l|}{ Photo (yes/no) } \\
\hline \multirow[t]{9}{*}{ Upper pouch } & \multirow[t]{3}{*}{ Inflammation features } & Severe erythema (yes/no) \\
\hline & & $\begin{array}{l}\text { Severe friability/contact bleeding } \\
\text { (yes/no) }\end{array}$ \\
\hline & & Erosion/ulceration (yes/no) \\
\hline & \multirow[t]{3}{*}{ Inflamed surface } & Affected (\%—where) \\
\hline & & Ulcerated (\%—where) \\
\hline & & $\begin{array}{l}\text { Inflamed suture lines only } \\
\text { (yes/no) }\end{array}$ \\
\hline & \multicolumn{2}{|l|}{$\begin{array}{l}\text { Other abnormalities } \\
\text { (eg, polyps) }\end{array}$} \\
\hline & \multicolumn{2}{|l|}{ Biopsy (yes/no) } \\
\hline & \multicolumn{2}{|l|}{ Photo (yes/no) } \\
\hline \multirow[t]{4}{*}{ Pouch inlet } & Stenosis (yes/no) & \\
\hline & $\begin{array}{l}\text { Other abnormalities } \\
\text { (eg, polyps) }\end{array}$ & \\
\hline & Biopsy (yes/no) & \\
\hline & Photo (yes/no) & \\
\hline Pre-pouch ileum & Distance intubated $(\mathrm{cm})$ & Aim for minimum of $20 \mathrm{~cm}$ \\
\hline & Strictures (yes/no) & \\
\hline & Inflammation features & Severe erythema (yes/no) \\
\hline & & $\begin{array}{l}\text { Severe friability/contact bleeding } \\
\text { (yes/no) }\end{array}$ \\
\hline & & Erosion/ulceration (yes/no) \\
\hline & Inflamed surface & Length of inflammation (cm) \\
\hline & & Continuous/skipped lesions \\
\hline & $\begin{array}{l}\text { Other abnormalities } \\
\text { (eg, polyps) }\end{array}$ & \\
\hline & Biopsy (yes/no) & \\
\hline & Photo (yes/no) & \\
\hline Others & Stool consistency & \\
\hline & Measure pouch size & $\begin{array}{l}\text { Anal verge-anastomosis-pouch } \\
\text { inlet }\end{array}$ \\
\hline
\end{tabular}


Table 2 Documentation of anatomical sites before and after introduction of the template

\begin{tabular}{|c|c|c|c|}
\hline Anatomical sites & $\begin{array}{l}\text { Before } \\
\text { introduction, } \\
\mathrm{N}(\%)\end{array}$ & $\begin{array}{l}\text { After } \\
\text { introduction, } \\
\mathrm{N}(\%)\end{array}$ & $P$ values \\
\hline Anus and perianal area & $15 / 121(12 \%)$ & $32 / 63(51 \%)$ & $<0.0001$ \\
\hline Rectal cuff & $66 / 121(55 \%)$ & $47 / 63(75 \%)$ & 0.01 \\
\hline $\begin{array}{l}\text { Pouch-anal } \\
\text { anastomosis }\end{array}$ & $45 / 121(37 \%)$ & $42 / 63(67 \%)$ & 0.0002 \\
\hline Pouch body & $118 / 120(98 \%)$ & $61 / 63(97 \%)$ & 0.61 \\
\hline Pouch inlet & $16 / 119(13 \%)$ & $26 / 63(41 \%)$ & $<0.0001$ \\
\hline Prepouch ileum & $72 / 119(61 \%)$ & 49/63 (78\%) & 0.12 \\
\hline
\end{tabular}

Bold indicates $P<0.05$.

retrospectively. These were obtained using a search of the endoscopy reporting platform.

Subsequently, the use of template by endoscopists was implemented between 12 August 2015 and 2 November 2015. The template was implemented as a paper-based endoscopy reporting tool and reports were written in the local electronic endoscopy software system. Each endoscopist was briefed on how to use the template before performing a pouchoscopy.

The template was used to monitor the standard of reporting prospectively and the feasibility of its use in day-to-day work at the same time.

Data collected included patient demographics such as age, gender, initial diagnosis prior to RPC-IPAA and level of endoscopist (consultant/registrar/specialised endoscopy nurse). All reports were scored against to the list of items on the template.

\section{RESULTS}

The reports of 121 consecutive flexible pouchoscopies performed before introduction of the template were reviewed. In 119 of these procedures (98\%), the endoscopist was able to perform a full procedure. In one case, the pouch could not be entered due to a stricture at the IPAA. In a second case, it was difficult to assess the pouch because of poor views due to poor bowel preparation. Documentation of inspection of the different anatomical regions of the template is shown in the first column of table 2 and of findings in the first column of table 3 .

The reports of 63 flexible pouchoscopies performed after the introduction of the template were reviewed and the results are also presented in tables 2 and 3 .

Comparing pouchoscopy reports before and after introduction of the template, documentation improved significantly for four anatomical sites. The anus and perianal area was mentioned in $15 / 121(12 \%)$ of reports before introduction of the template and in $32 / 63(51 \%)$ of reports after introduction $(\mathrm{p}<0.0001)$. For the rectal cuff, there was an increase in documentation from $66 / 121(55 \%)$ to $47 / 63(75 \%)(p=0.01)$; for the pouch-anal anastomosis, there was an increase from $45 / 121(37 \%)$ to $42 / 63(67 \%)(p=0.0002)$ and
Table 3 Documentation of individual features before and after introduction of the template

\begin{tabular}{|c|c|c|c|}
\hline $\begin{array}{l}\text { Anatomical sites and } \\
\text { features }\end{array}$ & $\begin{array}{l}\text { Before } \\
\text { introduction, } \\
\mathrm{N}(\%)\end{array}$ & $\begin{array}{l}\text { After } \\
\text { introduction, } \\
\mathrm{N}(\%)\end{array}$ & $P$ values \\
\hline \multicolumn{4}{|l|}{ Anus and perianal area } \\
\hline Digital examination & 9/121 (7\%) & $36 / 63(57 \%)$ & $<0.0001$ \\
\hline Abnormalities & $9 / 121(7 \%)$ & $29 / 63(46 \%)$ & $<0.0001$ \\
\hline \multicolumn{4}{|l|}{ Rectal cuff } \\
\hline Length & $5 / 121(45 \%)$ & $31 / 63(49 \%)$ & $<0.0001$ \\
\hline Inflammation & $10 / 121(8 \%)$ & $18 / 61^{*}(30 \%)$ & 0.0004 \\
\hline Abnormalities & $35 / 121(29 \%)$ & $36 / 61^{*}(59 \%)$ & 0.0001 \\
\hline Biopsy & $45 / 121(37 \%)$ & $32 / 61^{*}(52 \%)$ & 0.06 \\
\hline \multicolumn{4}{|l|}{ Pouch-anal anastomosis } \\
\hline Patency & $20 / 121(17 \%)$ & $41 / 63(65 \%)$ & $<0.0001$ \\
\hline Defects & $3 / 121(2 \%)$ & $23 / 63(41 \%)$ & $<0.0001$ \\
\hline \multicolumn{4}{|l|}{ Pouch body } \\
\hline Upper/lower & $45 / 120(38 \%)$ & $38 / 63(60 \%)$ & 0.005 \\
\hline Inflammation & $71 / 120(59 \%)$ & $44 / 63(70 \%)$ & 0.20 \\
\hline Extent† & $33 / 54(61 \%)$ & $14 / 19(74 \%)$ & 0.41 \\
\hline Abnormalities & $59 / 120(49 \%)$ & $48 / 63(76 \%)$ & 0.0005 \\
\hline Biopsy & $90 / 120(75 \%)$ & $41 / 63(65 \%)$ & 0.1707 \\
\hline \multicolumn{4}{|l|}{ Pouch inlet } \\
\hline Patency & $8 / 119(7 \%)$ & $17 / 62(27 \%)$ & 0.0004 \\
\hline Abnormalities & $6 / 119(5 \%)$ & $13 / 62(21 \%)$ & 0.002 \\
\hline Biopsy & $1 / 119(1 \%)$ & $6 / 62(10 \%)$ & 0.007 \\
\hline \multicolumn{4}{|l|}{ Prepouch ileum } \\
\hline Distance of intubation & $12 / 119(10 \%)$ & $31 / 59(53 \%)$ & $<0.0001$ \\
\hline Patency & $4 / 119(3 \%)$ & $21 / 59(36 \%)$ & $<0.0001$ \\
\hline Inflammation & $15 / 119(13 \%)$ & $24 / 59(41 \%)$ & $<0.0001$ \\
\hline Extent† & $4 / 12(33 \%)$ & $3 / 4(75 \%)$ & 0.26 \\
\hline Abnormalities & $8 / 119(7 \%)$ & $23 / 59(39 \%)$ & $<0.0001$ \\
\hline Biopsy & $24 / 119(20 \%)$ & $12 / 59(20 \%)$ & 1.0000 \\
\hline
\end{tabular}

*Two reports described the absence of a rectal cuff.

†The extent of the inflammation could only be described if there was inflammation.

Bold indicates $\mathrm{P}<0.05$.

for the pouch inlet it increased from $16 / 119$ (13\%) to 26/63 (41\%) $(\mathrm{p}<0.0001)$ (table 2).

Analysis of the individual features of importance at each anatomical site showed a statistically significant improvement in documentation in 15 out of 22 features (68\%) (table 3).

For the documentation of the feature 'inflammation', it was determined how often normal findings, namely, the absence of inflammation, were described in the pouchoscopy reports. Three anatomical sites require a description of the presence or absence of inflammation, namely, the rectal cuff, the pouch body and the prepouch ileum. The documentation of normal or negative findings improved statistically significantly for all three anatomical sites. Before introduction of the template, the absence of inflammation at the rectal cuff was described in 3\% (4/121) and after introduction this increased to $18 \%(11 / 61)(p=0.001)$. For the 
pouch body, documentation of the absence of inflammation improved from $14 \%(17 / 120)$ to $38 \%(24 / 63)$ $(\mathrm{p}=0.0004)$ and for the prepouch ileum, it improved from $3 \%(3 / 119)$ to $34 \%(20 / 59)(\mathrm{p}<0.0001)$.

\section{DISCUSSION}

Variation in quality of reporting on endoscopic procedures is a common clinical problem and has led to studies addressing the adequacy of reports. ${ }^{45}$ The Canadian Association of Gastroenterology created guidelines on safety and quality indicators in endoscopy, which recommend that endoscopic reports should be completed in a standardised manner. ${ }^{6}$ They also identified a clear need for high-quality research to support quality improvement in the delivery of endoscopy services. However, the majority of these studies were performed to improve reporting on colonoscopies in the context of colorectal cancer screening, and there are almost no studies that specifically address reporting on pouchoscopy. One recent paper by Devlin $e t a l^{7}$ developed recommendations for quality reporting of colonoscopy procedures in inflammatory bowel disease, which included some recommendations for the reporting of pouchoscopies. However, there has been almost no publication about performing pouchoscopy in a standardised manner.

In this study, a group of ileo-anal pouch experts at a tertiary centre developed a list of anatomical sites that should be documented in a flexible pouchoscopy report and their specific features. Consensus was achieved to form a reporting template for standardised documentation of flexible pouchoscopy using series of constructive discussion and meetings. Such a template has potential value in a systematic assessment of pouch dysfunction, making it easier to compare findings of multiple pouchoscopies of the same patient, which will contribute to current and future therapeutic decisions. At the same time, it could facilitate research and audit, since there will be more consistency of reporting findings during pouchosopy. Finally, it could be a useful practical guidance to be followed by endoscopists while performing the pouchoscopy, in particular in centres with low volumes of pouchoscopic assessment. It provides a comprehensive overview of information required in order to create a high quality flexible pouchoscopy report.

The review of the quality of flexible pouchoscopy reports prior to the introduction of the template showed poor documentation of visualisation especially of the anus and perianal area (12\%), the ileal pouch-anal anastomosis (37\%) and the pouch inlet $(13 \%)$. All of them were not mentioned in over two-third of the cases. The quality of documentation is unlikely to be related to the performance quality of pouchoscopy; inspection of the perianal area and anus were documented poorly before the introduction of the template, but no pouchoscopy can be performed without examining this area. This also applies to the performance of a digital examination, which is performed in majority of cases, but not often documented. After implementation of the template, documentation of examination of the anus and perianal area quadrupled. This suggests that the template encouraged endoscopists to actively document their routine practice.

Overall, introduction of this standardised template for pouchoscopy reports was associated with significant improvement in documentation. Considering this by anatomical site, there was an improvement in five out of six sites (of which four were statistically significant). Documentation of the pouch body showed no improvement, but was well reported before the intervention. However, there was an increase in the reporting rate of four out of five pouch body-specific features. This improvement was significant in two features, namely, describing the upper and lower pouch body separately and reporting abnormalities. In general, it can be concluded that the template improved documentation for all anatomical sites. Furthermore, $68 \%$ of the individual features showed a statistically significant improvement.

A secondary aim of this study was to try to improve the documentation of normal findings. Documentation of absence of inflammation significantly improved in all three anatomical sites. However, even after the introduction of the template, documentation remained suboptimal for some anatomical sites. Although documentation of the pouch inlet showed a significant improvement, it was only mentioned in $41 \%$ of the reports after template introduction. This finding underlines the need for ongoing education of endoscopists undertaking pouchoscopy.

Limitations of this study include the development of the reporting template at a single centre in consultation with a relatively small number of experts. This means the included sites and items are mainly based on opinions of the experts; however, all those involved were experienced and work in a centre undertaking a high volume of pouch surgery and pouch endoscopy. Furthermore, the process of developing the template did not entirely adhere to the Dephi-methods for consensus building. For example, the process did not start with an openended questionnaire and the template was only reviewed twice instead of the usual three times. Devlin et al (2016) used a panel of 13 gastroenterologists engaged in inflammatory bowel disease research from four different countries compiled a list of elements according to the RAND/University of California, Los Angeles appropriateness method. ${ }^{7}$ All the endoscopic elements they recommended are included in the template presented in this study. Our template was more extensive in terms of the description of the inflammation, which required a more detailed description of the type and the extent of inflammation, not only its presence or absence. By 
individually describing the different features of the inflammation present and the percentage of surface affected, a sliding scale of scoring inflammation arises and progression or regression of disease can probably be better assessed. Additional items in our template are a description of the anastomosis and of the pouch size. We would recommend retaining these features in the template, since the anastomosis is an important landmark, ${ }^{3}$ structuring is a common

\section{Significance of this study}

\section{What is already known on this topic}

- Variation in quality of reporting on endoscopic procedures is a common clinical problem and has led to studies addressing the adequacy of reports. Findings are often not documented in a standardised manner and there is a tendency towards reporting abnormal findings only. Normal or negative findings are not always documented, but may be equally important in the diagnostic or therapeutic process. The majority of these studies were performed to improve reporting on colonoscopies in the context of colorectal cancer screening. However, this tendency of not reporting on normal findings is also seen in the reporting of pouchoscopy. Additionally, since the anatomy is entirely different after restorative proctocolectomy with the formation of ileal pouchanal anastomosis, the assessment of ileo-anal pouches should involve documentation of specific anatomical sites and specific elements that can be the cause of pouch dysfunction, which makes it difficult to use current colonoscopy reporting tools as a guide.

\section{What this study adds}

- This study aimed to improve overall reporting on pouchoscopy and to reach consensus on which specific items should be described in a pouchoscopy report. Secondary, this template was then introduced and quality of reports was analysed prospectively.

\section{How might it impact on clinical practice in the foreseeable future}

- Such a template has potential value in a systematic assessment of pouch dysfunction, making it easier to compare findings of multiple pouchoscopies of the same patient, which will contribute to current and future therapeutic decisions. At the same time, it could facilitate research and audit, since there will be more consistency of reporting findings during pouchoscopy. Finally, it could be a useful practical guidance to be followed by endoscopists while performing the pouchoscopy, in particular in centres with low volumes of pouchoscopic assessment. It provides a comprehensive overview of information required in order to create a high quality flexible pouchoscopy report. problem and a defect may be associated with pelvic sepsis, which can mimic pouchitis. ${ }^{8}$ Abnormal pouch size (either capacious or too small) is another important, though rare, cause of pouch dysfunction. It might be valuable to set up a study that involves more pouch experts around the country, Europe and beyond, and use well-established methods to reach consensus on important and feasible items in order to refine this template, as there are clear benefits of a standardised template. Such standardisation should make findings more transferable and facilitate more comparative and collaborative research.

Regarding the data showing that implementation of the template improved reporting rates, the study was limited by fewer reports being included in the prospective part of the study. Furthermore, endoscopists who used the template knew their reports were being evaluated, so the observed improvement might have been a result of the study itself rather than the template. Creating specific reporting software with standardised fields may be more efficient, user-friendly and timesaving for endoscopists to complete compared with handwriting report we used in this study. ${ }^{5}$

In summary, introduction of a standardised reporting template for pouchoscopy improves documentation in general, including documentation of normal/negative findings and documentation within the different levels of endoscopists.

Acknowledgements The work described in this paper was undertaken as part of a Research Internship, Faculty of Medicine, University of Groningen and the resulting essay is available at http://scripties.umcg.eldoc.ub.rug.nl/FILES/root/ geneeskunde/2016/PloegVvander/PloegvanderV.pdf

Contributors VAvdP performed and managed the study, collected and analysed the data, wrote the paper and submitted the study. YM assisted with performing the study, analysing the data and writing the paper. ODF, ALH and SKC were the clinical experts and contributed to the design of the study, the content of the pouchoscopy reporting template and revised the paper.

Funding The authors have not declared a specific grant for this research from any funding agency in the public, commercial or not-for-profit sectors.

Competing interests None declared.

Patient consent Not required.

Provenance and peer review Not commissioned; externally peer reviewed.

(C) Article author(s) (or their employer(s) unless otherwise stated in the text of the article) 2018. All rights reserved. No commercial use is permitted unless otherwise expressly granted.

\section{REFERENCES}

1 Fazio VW, Kiran RP, Remzi FH, et al. Ileal pouch anal anastomosis: analysis of outcome and quality of life in 3707 patients. Ann Surg 2013;257:679-85.

2 McLaughlin SD, Clark SK, Tekkis PP, et al. Review article: restorative proctocolectomy, indications, management of complications and follow-up-a guide for gastroenterologists. Aliment Pharmacol Ther 2008;27:895-909.

3 McLaughlin SD, Clark SK, Thomas-Gibson S, et al. Guide to endoscopy of the ileo-anal pouch following restorative 
proctocolectomy with ileal pouch-anal anastomosis; indications, technique, and management of common findings. Inflamm Bowel Dis 2009;15:1256-63.

4 Lieberman DA, Faigel DO, Logan JR, et al. Assessment of the quality of colonoscopy reports: results from a multicenter consortium. Gastrointest Endosc 2009;69(3 Pt 2):645-53.

5 de Jonge V, Sint Nicolaas J, Cahen DL, et al. Quality evaluation of colonoscopy reporting and colonoscopy performance in daily clinical practice. Gastrointest Endosc 2012;75:98-106.

6 Armstrong D, Barkun A, Bridges R, et al. Canadian Association of Gastroenterology consensus guidelines on safety and quality indicators in endoscopy. Can J Gastroenterol 2012;26:17-31.

7 Devlin SM, Melmed GY, Irving PM, et al. Recommendations for quality colonoscopy reporting for patients with inflammatory bowel disease: Results for a RAND appropriateness panel. Inflamm Bowel Dis 2016;22:1418-24.

8 van der Ploeg VA, Maeda Y, Faiz OD, et al. The prevalence of chronic peri-pouch sepsis in patients treated for antibioticdependent or refractory primary idiopathic pouchitis. Colorectal Dis 2017;19:827-31. 